\title{
Farmers Knowledge on Emerging Marketing Interventions of Fruits and Vegetables in Karnataka, India
}

\author{
G. N. Gayathri ${ }^{1 *}$, S. Sahana ${ }^{2}$, Basavaraj I. Halingali ${ }^{2}$ and Nagarajappa Adivappar ${ }^{2}$ \\ ${ }^{1}$ Division of Dairy Extension, ICAR-National Dairy Research Institute, \\ Karnal, Haryana, India \\ ${ }^{2}$ College of agriculture, UAHS, Shivamogga, Karnataka, India \\ *Corresponding author
}

\section{Keywords}

Knowledge, Public market intervention,

Co-operative market intervention, Private market intervention

\section{Article Info}

Accepted:

05 April 2020

Available Online:

10 May 2020

\begin{abstract}
A B S T R A C T
The present study was conducted in Davangere district of Karnataka state during 2017-18.

For the study, 40 farmers each from public, co-operative and private market intervention were selected following simple random sampling procedure. Thus, the total sample size constituted to 120 . The data was collected using pre-tested questionnaires. The knowledge level of farmers was measured considering criteria like General information, post-harvest activities and Market related information by framing different statements. The data was analyzed using excel and results was presented in frequency and percentage. The findings of the study indicated that the farmers had cent percent knowledge on awareness, grading procedure, packing, transit loss, Electronic weighment services, Acceptance of produce irrespective of quality and quantity and market updates in Public market intervention. In case of Co-operative market intervention, the farmers had full knowledge $(100.00 \%)$ on awareness, harvesting procedure for HOPCOMS and branding of the produce under HOPCOMS trade name. The Private market farmers had same knowledge $(100.00 \%)$ on awareness, grading and mechanical grading, establishment of local market and collection centers, timely co-operation of staff and monitoring of farming activities. The study reflects that the farmers are having fair knowledge in all three market interventions.
\end{abstract}

\section{Introduction}

Agriculture in India has two important components. One is the production and another is marketing of the produce. Farmers role is up to production aspect where their efforts are more but the profit is mainly depending on the effective and efficient marketing of the produce. The country has witnessed a great stride in agriculture production, especially with the introduction of improved farm technology during the "green revolution" period. Horticulture takes a prominent place among other sectors of agriculture by being blessed with the unique gift of nature, like abundant sunshine hours, different soil types and other agro-climatic conditions. With varied agro climatic 
conditions, India is able to grow an array of fruits and vegetables exceeding 100 types.

Karnataka enjoys a prominent place in the production of horticultural crops. The state provides a congenial atmosphere for the production of horticultural crops both under rain fed and irrigated conditions as well. The fruits and vegetables being perishable commodities having less shelf life and there is a need for special kind of marketing as it is a time-bound activity. Thus, marketing of fruits and vegetables is subjected to price fluctuations, which is exploited by the middleman. Apart from this, there has always been a debate on providing remunerative price to farmers and at the same time an affordable price to consumers. This focuses on the issue of marketing with a thrust to reduce the price strategies between the primary producers and ultimate consumers. The study has been taken up to know the knowledge of the farmers about different market interventions for their crops. So that the farmers can know about the prices and other market related information necessary for sale of produce at reasonable price.

\section{Materials and Methods}

The study was conducted in Davanagere district of Karnataka state in 2017-18. The district was purposively selected based on the functioning of public, co-operative and private institutional market interventions. From these institutional interventions APMC (Agricultural Produce Market Committee) was selected under public, HOPCOMS (Horticultural Producers' Cooperative Marketing and Processing Society) under cooperative and Big Bazaar and Reliance Fresh were selected under private. From each intervention, 40 farmers growing fruits and vegetables were selected. Thus, total sample size for the study was 120 . The pertinent data was collected from the sample farmers using pre-tested interview schedule. A schedule was developed to measure the knowledge level of respondents. A large number of statements were collected under different headings to assess the knowledge level of farmers about public, co-operative and private institutional market intervention. For this purpose, all possible knowledge items were developed from a review of the literature, discussion with experts, agricultural scientists and farmers. In these processes finally most suitable 36 items, which includes 'Yes/No' statements and 10 multiple choice questions were selected and included in the schedule. The score of one was given for 'Yes' response and zero for 'No' response, for each right answer in subquestion a score of one was given. The individual score was obtained by summing up the scores for all the statements. The maximum score one could obtain was 46 and the minimum score could be zero. The respondents were grouped into three categories based on the mean and standard deviation as a measure of the check. The results were expressed in frequency and percentages.

\section{Results and Discussion}

\section{Overall knowledge level of the farmers on institutional market interventions}

The data depicted in Table 1 indicate that, respondents were having medium level of knowledge in case of public $(72.50 \%)$, cooperative $(70.00 \%)$ and private $(70.00 \%)$ market intervention.

In all the three cases farmers were having medium level of knowledge due to accessibility of the market to farming community. Present information technology and also education level of the farmers might have influenced them to have medium to high level of knowledge. 
Int.J.Curr.Microbiol.App.Sci (2020) 9(5): 720-728

Table.1 Overall knowledge level of farmers on institutional market interventions

\begin{tabular}{|c|c|c|c|c|c|c|c|c|c|}
\hline \multirow[b]{2}{*}{ Category } & \multicolumn{3}{|c|}{$\operatorname{Public}\left(\mathrm{n}_{1}=40\right)$} & \multicolumn{3}{|c|}{ Co-operative $\left(n_{2}=40\right)$} & \multicolumn{3}{|c|}{$\begin{aligned} & \mathrm{n}=120 \\
& \operatorname{Private}\left(\mathrm{n}_{3}=40\right)\end{aligned}$} \\
\hline & Criteria & f & $\%$ & Criteria & $\mathbf{F}$ & $\%$ & Criteria & $\mathbf{f}$ & $\%$ \\
\hline Low $(<\bar{x}-$ SD) & $<41.12$ & 6 & 15.00 & $<36.72$ & 4 & 10.00 & $<32.32$ & 2 & 5.00 \\
\hline $\begin{array}{c}\operatorname{Medium}(\bar{x} \pm \\
\text { SD) }\end{array}$ & $41.12-45.98$ & 29 & 72.50 & $36.72-41.53$ & 28 & 70.00 & $32.32-36.98$ & 28 & 70.00 \\
\hline High $(>\bar{x}+$ SD $)$ & $>45.98$ & 5 & 12.50 & $>41.53$ & 8 & 20.00 & $>36.98$ & 10 & 25.00 \\
\hline
\end{tabular}

$\mathrm{f}=$ Frequency

$\%$-Percentage 
Table.2 Knowledge level of farmers on Public market intervention (APMC)

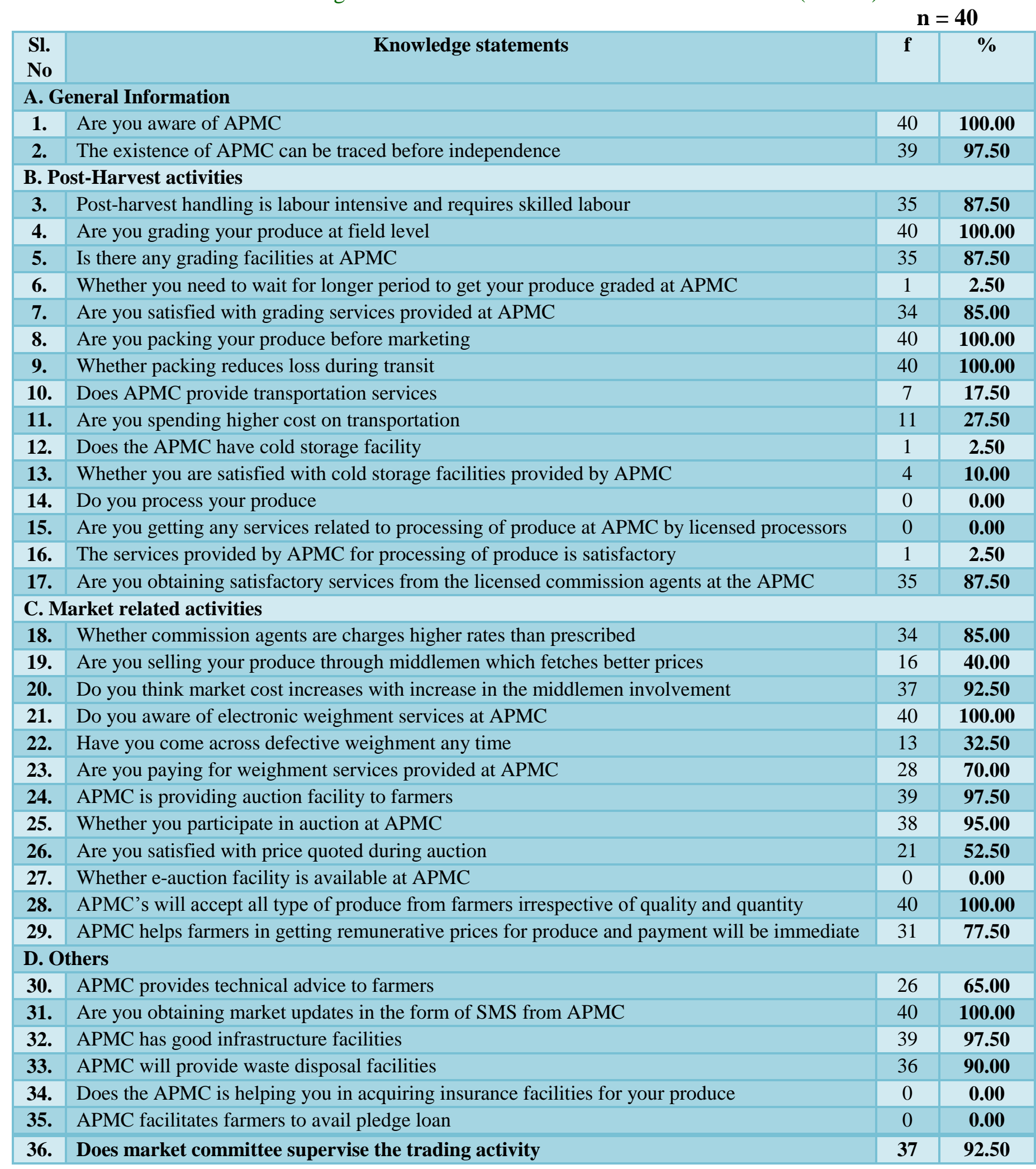


Table.3 Knowledge level of farmers on Co-operative market intervention (HOPCOMS)

\begin{tabular}{|c|c|c|c|}
\hline \multirow{2}{*}{ Sl. No } & \multirow[b]{2}{*}{ Knowledge statements } & \multicolumn{2}{|c|}{$n=40$} \\
\hline & & $\mathbf{f}$ & $\%$ \\
\hline \multicolumn{4}{|c|}{ A. General Information } \\
\hline 1 & Are you aware of HOPCOMS, a co-operative society & 40 & 100.00 \\
\hline 2 & Are you aware of rules and regulations of HOPCOMS & 36 & 90.00 \\
\hline 3 & HOPCOMS is working since from last 50 years & 27 & 67.50 \\
\hline 4 & Are you a member of HOPCOMS & 33 & 82.50 \\
\hline 5 & Whether you harvest the produce as per the requirements of HOPCOMS & 40 & 100.00 \\
\hline \multicolumn{4}{|c|}{ B. Post-Harvest activities } \\
\hline 6 & Post-harvest handling is labour intensive which requires skilled labour & 39 & 97.50 \\
\hline 7 & Are you grading your produce at field level to reap the advantages of grading & 37 & 92.50 \\
\hline 8 & Is there any grading facilities at HOPCOMS & 0 & 0.00 \\
\hline 9 & Whether you need to wait for longer period to get your produce graded at HOPCOMS & 5 & 12.50 \\
\hline 10 & Are you packing your produce before marketing & 34 & 85.00 \\
\hline 11 & Do you think packing reduces transit loss & 35 & 87.50 \\
\hline 12 & Does HOPCOMS provide transportation services & 2 & 5.00 \\
\hline 13 & Are you spending higher cost on transportation & 10 & 25.00 \\
\hline 14 & Does the HOPCOMS have cold storage facility & 0 & 0.00 \\
\hline 15 & Whether you are satisfied with cold storage facilities provided by HOPCOMS & 0 & 0.00 \\
\hline 16 & Do you process your produce & 0 & 0.00 \\
\hline 17 & $\begin{array}{l}\text { Are you getting any services related to processing of produce at HOPCOMS given by licensed } \\
\text { processors }\end{array}$ & 0 & 0.00 \\
\hline 18 & The services provided by HOPCOMS for processing of produce is satisfactory & 0 & 0.00 \\
\hline 19 & Are you branding your produce under HOPCOMS trade name which fetches higher price & 40 & 100.00 \\
\hline 20 & Are you aware of electronic weighment services at HOPCOMS & 36 & 90.00 \\
\hline 21 & Have you come across defective weighment any time & 12 & 30.00 \\
\hline 22 & Are you paying for weighment services provided at HOPCOMS & 26 & 65.00 \\
\hline 23 & Are you satisfied with prices announced by HOPCOMS & 29 & 72.50 \\
\hline 24 & HOPCOMS will accept all type of produce from farmers irrespective of quality and quantity & 14 & 35.00 \\
\hline 25 & HOPCOMS has its own quality standards & 37 & 92.50 \\
\hline 26 & HOPCOMS is providing remunerative prices for produce where in payment is immediate & 30 & 75.00 \\
\hline \multicolumn{4}{|c|}{ C. Market related activities } \\
\hline 27 & HOPCOMS is providing technical advice, market information and inputs to farmers & 9 & 22.50 \\
\hline 28 & HOPCOMS is supplying inputs to the farmers at reasonable prices & 0 & 0.00 \\
\hline 29 & HOPCOMS intervention reduces middlemen & 39 & 97.50 \\
\hline 30 & HOPCOMS has its own procurement and marketing outlets & 35 & 87.50 \\
\hline 31 & Whether HOPCOMS assists in claiming insurance facilities for your produce & 0 & 0.00 \\
\hline 32 & Whether market committee supervises the trade activity & 39 & 97.50 \\
\hline \multicolumn{4}{|c|}{ D. Others } \\
\hline 33 & Are you obtaining adequate and timely co-operation from the HOPCOMS and its staff & 35 & 87.50 \\
\hline 34 & HOPCOMS is conducting regular meetings for member farmers & 17 & 42.50 \\
\hline 35 & HOPCOMS is involved in advertisement of its products to promote sales & 38 & 95.00 \\
\hline 36 & HOPCOMS is involved in conducting training to farmers & $\mathbf{0}$ & 0.00 \\
\hline
\end{tabular}

Note: Responses are mutually inclusive

f- Frequency $\%$ - Percentage 
Table.4 Knowledge level of farmers on Private market intervention (Big Bazaar and Reliance Fresh)

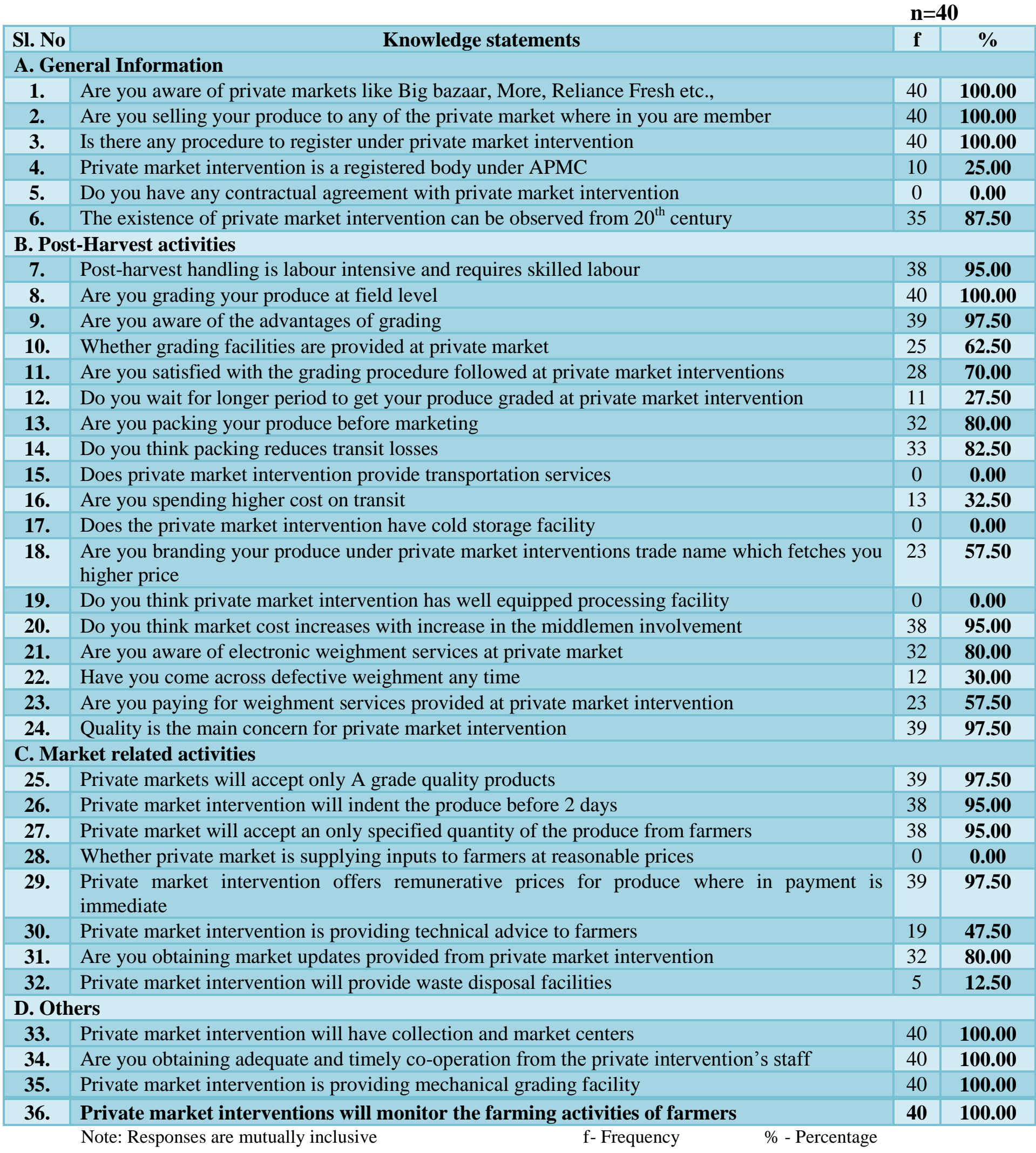


Photo: Researcher with the farmers at fields during data collection at Davangere taluk
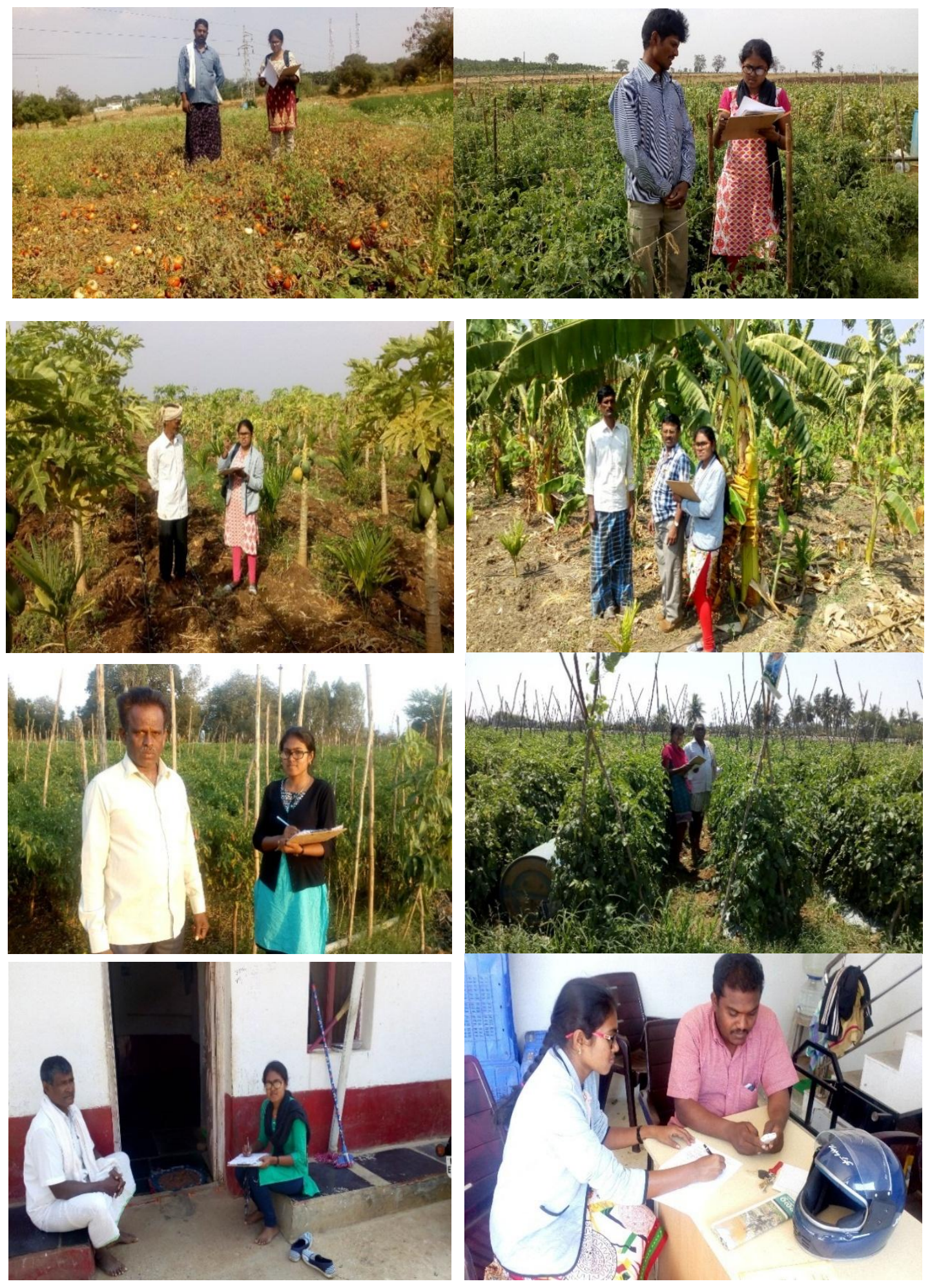
In case of public sector (APMC) is having slightly high level of knowledge due to long period of existence and accessible by all the farmers for all the crops irrespective of quality and quantity.

\section{Knowledge level of the farmers on public market interventions}

The results in Table 2 indicates that farmers had complete knowledge (100.00 \%) on awareness, grading procedure, packing, transit loss, electronic weighment services, acceptance of produce irrespective of quality and quantity and market updates through SMS. They lack knowledge on processing, eauction, insurance and pledge loan facility.

This might be due to the fact that, all these facilities were available at APMC and farmers were actively involved in all these activities as this was a mandatory work for many crops sold at APMC. Processing, e-auction, pledge loan and insurance facility was not available at study area and farmers were not exposed to it.

\section{Knowledge level of the farmers on co- operative market interventions}

Cent pent of farmers had same knowledge $(100.00 \%)$ on awareness, harvesting procedure for HOPCOMS and branding of the produce under HOPCOMS trade name and reducing middle men. This might be due to the fact that HOPCOMS having its own standards, quality requirements and marketing strategies of the produce. This made the farmers to have a complete knowledge on that to prepare the product for getting better price in the co-operative market intervention. Even though they had knowledge, they lack knowledge on processing, cold storage, insurance and supply of input due to fact that HOPCOMS was mainly involved in direct purchasing of quality produce from farmers and selling to customers for better profit. This might be the reason for having lack of knowledge on all these aspects.(Table 3)

\section{Knowledge level of the farmers on private market interventions}

The data in Table 4 depicts that in case of private market the farmers had complete knowledge (100.00\%) on awareness, grading, establishment of local market and collection centers, timely co-operation and monitoring. In private market intervention, buyers are more specific about the grading of the quality produce to full fill the requirements of global market. To get more quantity product, they used to monitor the crop at every stage and provide better collection and transportation services to avoid the post-harvest handling loses of the produce. This might have been influenced for the following result. They lack knowledge on processing, cold storage activities were taken care by the buyers.

In conclusion, the present study focused on assessing the knowledge level of farmers on emerging institutional market interventions. It was found that sampled farmers had high knowledge on General information in all the three categories of markets. Whereas in case of post-harvest activities and market related activities, the farmers have less knowledge. So, there is need to provide information and education related to marketing of the fruits and vegetables through different extension functionaries at different market channels. The action could be taken by authorities of these market interventions to provide all the facilities relate to marketing to farmers.

\section{References}

1. Ravi Shankar, G. T., Awareness of member-producers and opinion of consumers towards the functioning of HOPCOMS Ltd., M.Sc. (Agri.) Thesis, 
Univ. Agric. Sci., Bangalore, marketing institutions in Karnataka, Karnataka, 2001. M.Sc. (Agri.) Thesis, Univ. Agric. Sci.,

2. Shashi, M., A study on farmers Bangalore, Karnataka, 2009. awareness and preferences towards organized fruits and vegetables

\section{How to cite this article:}

Gayathri, G. N., S. Sahana, Basavaraj I. Halingali and Nagarajappa Adivappar. 2020. Farmers Knowledge on Emerging Marketing Interventions of Fruits and Vegetables in Karnataka, India. Int.J.Curr.Microbiol.App.Sci. 9(05): 720-728. doi: https://doi.org/10.20546/ijcmas.2020.905.080 